\title{
A NOTE ON REFERENCES
}

The format for citations of documents released by the FBI under the Freedom of Information Act follows that used in the F B I's central filing system. A citation such as "WFOIOO-354492-3:3" indicates FBI file number I00-354492-3, page 3. The letter abbreviation refers to the location of the file; e.g., "WF O" indicates "Washington Field Office," or F B I headquarters. (Other location abbreviations used are listed at the opening of the bibliography.) The first series of numbers - in the example, roo-indicates a "domestic security" file entry; " 65 ” indicates "espionage"; “67" indicates "personnel matters," and so forth. For more on the F B I's central records classification codes, see Buitrago and Immerman I98I; Theoharis I994. Some variations on this citation format are found in this book - for example, the letters " $\mathrm{A}$ " or " $\mathrm{X}$ " at times appear in citations, and page number citations are frequently missing. These and other variations only reflect my rendering of the exact FBI notations appearing on the cited files. I provide dates and page numbers where available, and do not attempt to interject this data where it is missing on the FBI files. Occasionally files from other federal agencies (such as the Department of Energy and the CIA) are cited using the archival formats of these agencies.

A list of archival and manuscript sources used also appears at the start of the bibliography, along with the abbreviation used for each source. Cita- 
xviii A Note on References

tions in the text are keyed to this list. In-text citations also include the location code information used by the individual archive or manuscript holder. For example, "MJ: I20, 52" indicates the "Melville Jacobs Papers, Special Collections, University of Washington"; " 120 ” indicates box number, and " 52 " indicates folder 52. Correspondence and papers from other collections follow internally consistent formats used by specific archives or manuscript collections.

Periodical publications frequently cited are also indicated by abbreviations in the text keyed to this list in the bibliography. Those with no specific volume information appear as abbreviation and date. Those with additional facts of publication include such information in the cite; for example, "AAANB I948 2(5): 72-73" indicates volume 2, number 5, pp. 72-73, of the 1948 News Bulletin of the AAA.

Personal correspondence is indicated in the text only, for example, "Doe to Price $12 / \mathrm{I} / 99$ " indicates letter to the author from Doe on date given. Finally, interviews are also referenced directly in the text using a format such as "Peresypkin interview with Price 8/ı2/OI." 